\title{
BIOACUMULAÇÃO DE ZINCO EM MICÉLIO DE Agaricus subrufescens
}

\author{
Rafael de Carli Marcante ${ }^{1}$ \\ Adriano Meniquetti ${ }^{2}$ \\ Claudicéia Risso Pascotto ${ }^{3}$ \\ Zilda Cristiani Gazin ${ }^{3}$ \\ Hélida Mara Magalhães ${ }^{3}$ \\ Nelson Barros Colauto ${ }^{3}$ \\ Giani Andrea Linde ${ }^{3, *}$
}

MARCANTE, R. de C.; MENIQUETTI, A.; PASCOTTO, C. R.; GAZIN, Z. C.; MAGALHÃES, H. M.; COLAUTO, N. B.; LINDE, G. A. Bioacumulação de zinco em micélio de Agaricus subrufescens. Arq. Ciênc. Vet. Zool. UNIPAR, Umuarama, v. 17, n. 4 , p. 249-252, out./dez. 2014.

\begin{abstract}
RESUMO: Fungos basidiomicetos têm a capacidade de bioacumular metais pesados, no entanto existem poucos trabalhos sobre bioacumulação de zinco em micélio de Agaricussubrufescens. O objetivo deste trabalho foi avaliar a bioacumulação de zinco em micélio vegetativo de $A$. subrufescens cultivado em meio sólido e líquido. O fungo foi crescido em meio sólido ou em meio líquido a base de extrato de malte adicionado de $\mathrm{ZnSO}_{4}$ a fim de obter zero; 2,5; 5; 7,5; $10 ; 15$ ou 20 ppm de zinco. Os meios foram inoculados e após 14 dias foi determinada a biomassa e a bioacumulação de zinco. A adição de zinco no meio de cultivo inibiu o crescimento micelial e induziu a bioacumulação na biomassa tanto no cultivo sólido como no líquido. Adições acima de 7,5 ppm de zinco inibiram totalmente o crescimento micelial. O fungo crescido em meio de cultivo líquido sofre maior inibição do crescimento com a adição de zinco e maior bioacumulação que no meio sólido.
\end{abstract}

PALAVRAS-CHAVE: Agaricus blazei. Agaricus brasiliensis. Micélio. Ferro. Zinco.

\section{ZINC BIOACCUMULATION IN Agaricus subrufescens MYCELIUM}

\begin{abstract}
Fungi basidiomycetes have the ability to bioaccumulate heavy metals, but there are few studies on zinc bioaccumulation in the mycelium of Agaricus subrufescens. The objective of this study is to evaluate the zinc bioaccumulation in the mycelium of $A$. subrufescens cultivated in solid and liquid culture media. Mycelium was grown on solid or liquid medium in malt extract base added with $\mathrm{ZnSO}_{4}$ to obtain zero, 2.5, 5, 7.5, 10, 15 or 20-ppm zinc. Mycelial biomass and zinc bioaccumulation were determined 14 days after inoculation in the culture media. Addition of zinc in culture medium inhibited mycelial growth and induced biomass bioaccumulation both in solid and in liquid culture. Additions higher than 7.5-ppm zinc completely inhibited mycelial growth in culture medium. Mycelial growth in liquid culture presented greater increase of growth inhibition with the addition of zinc and greater bioaccumulation than in solid medium.
\end{abstract}

KEYWORDS: Agaricus blazei. Agaricus brasiliensis. Mycelium. Iron. Zinc.

\section{BIOACUMULACIÓN DE ZINC EN MICELIO DE Agaricus subrufescens}

RESUMEN: Hongos basidiomicetos tienen la capacidad de bioacumular metales pesados, sin embargo hay pocos estudios sobre la bioacumulación de zinc en el micelio de Agaricus subrufescens. El objetivo de este estudio ha sido evaluar la bioacumulación de zinc en el micelio de $A$. subrufescens cultivado en medio sólido y líquido. El hongo ha crecido en medio sólido o líquido a base de extracto de malta agregado de $\mathrm{ZnSO}_{4}$ para obtener cero; 2.5, 5, 7.5, 10, 15 o 20 ppm de zinc. Los medios fueron inoculados y después de 14 días se determinó la biomasa y la bioacumulación de zinc. La adición de zinc en el medio del cultivo inhibió el crecimiento micelial y indujo la bioacumulación de la biomasa tanto en el cultivo sólido como en el líquido. Adiciones superiores a 7.5 ppm de zinc inhibieron completamente el crecimiento del micelio. El hongo crecido en medio de cultivo líquido sufre mayor inhibición del crecimiento con la adición de zinc y mayor bioacumulación que en el medio sólido.

PALABRAS CLAVE: Agaricus blazei. Agaricus brasiliensis. Micelio. Hierro. Zinc.

\section{Introdução}

As deficiências de micronutrientes como o zinco são considerados um grande problema de saúde pública em muitos países em desenvolvimento e ocasionam diversos agravos à saúde (FAO, 2006). O zinco é um elemento traço com grande abundância intracelular. Esse composto está envolvido na síntese de proteínas e ainda como cofator de inúmeras enzimas metabólicas. O zinco participa ainda da regulação da atividade sináptica e dos processos neuronais e tem papel crítico na regulação da transcrição de genes e na síntese e no crescimento neuronal (ANDERSON; ERICKSON, 2009).

A deficiência de zinco não é incomum e normal-

DOI: https://doi.org/10.25110/arqvet.v17i4.2014.5025

${ }^{1}$ Acadêmico do Curso de Farmácia, Universidade Paranaense/UNIPAR, Rua Cambé 4340, Umuarama-PR, CEP. 87502-160, email: marcante@hotmail.com ${ }^{2}$ Acadêmico do Programa de Pós-graduaçãostricto sensu em Biotecnologia Aplicada à Agricultura, Universidade Paranaense/UNIPAR,Cx.P. 224, 87502-210 e-mail:adrianomeniquetti@hotmail.com

${ }^{3}$ Professor Titular do Programa de Pós-graduação stricto sensu em Biotecnologia Aplicada à Agricultura - Universidade Paranaense/UNIPAR. UmuaramaPR, Cx.P. 224, 87502-210, email: gianilinde@unipar.br 
mente está associada à deficiência de ferro devido às fontes alimentares e os compostos inibitórios da absorção serem semelhantes para ambos os metais. A deficiência de zinco gera um processo anormal do sistema nervoso, provocando efeitos comportamentais distintos (SANDSTEAD; FREDERICKSON; PENLAND, 2000). As deficiências de zinco estão diretamente associadas à redução desses elementos na dieta. Normalmente, para obtenção de alimentos com características sensoriais padronizadas, a indústria remove o gosto desagradável das matérias primas. Tais processos baseiam-se na remoção de fenóis, flavonoides, isoflavonas, terpenos, glucosinolatos, vitaminas, peptídos e minerais (LINDE; LAVERDE-JR; COLAUTO, 2011). Dessa forma, torna-se importante o desenvolvimento de alimentos funcionais com altos teores de nutrientes essenciais como os minerais.

A. subrufescens (Agaricus blazei; Agaricus brasiliensis) é um basidiomiceto com alto valor nutricional que apresenta atividades antitumoral (MOURÃO, 2008), antioxidante (DELMANTO et al., 2001), anti-inflamatória, antimutagênica (BRAGA et al., 1998) e imunomoduladora (FIRENZUOLI; GORI; LOMBARDO, 2008). Este fungo possui ainda a capacidade de bioacumulação metais e esta potencialidade poderia ser utilizada para bioacumular minerais de importância nutricional como o zinco. Apesar do potencial da produção de basidiomicetos funcionais enriquecidos com minerais, existem poucos relatos sobre a bioacumulação de zinco em micélio de A. subrufescens (MANTOVANI, 2008).

Este fungo por ser consumido principalmente na forma de basidiocarpos, também é utilizado para a maiora dos estudos de atividade biológica deste basidiomiceto (MANTOVANI, 2008). Entretanto, a produção micelial possui vantagens sobre a produção de cogumelos como o controle da presença de metais pesados e agrotóxicos que podem bioacumular-se no basidiocarpo. Além do maior controle a produção micelial pode ser realizada em menor tempo e com menor número de etapas e ainda proporciona a obtenção de outros compostos como exopolissacarídeos e enzimas (CHANG et al., 2001).

Dessa forma, o objetivo deste trabalho foi avaliar o efeito da adição de zinco ao meio de cultivo sólido ou líquido sobre o crescimento micelial de $A$. subrufescens e sua capacidade de bioacumulação desses minerais.

\section{Material e Métodos}

\section{Inóculo}

A. subrufescens (U2/1) pertencente à micoteca do Laboratório de Biologia Molecular da Universidade Paranaense, Campus Umuarama, mantido a $28{ }^{\circ} \mathrm{C}$ em ágar-extrato de malte (AEM) $\left(34 \mathrm{gL}^{-1}\right)$ foi transferido para AEM $\left(34 \mathrm{gL}^{-1}\right)$ e mantidos a $28{ }^{\circ} \mathrm{C}$, no escuro, durante 20 dias. Após a recuperação do vigor do crescimento micelial selecionou-se micélio com ramificação homogênea, sem setoriamento, como inóculo.

\section{Meio de Cultivo Sólido}

O meio de cultivo AEM $\left(34 \mathrm{gL}^{-1}\right)$ foi autoclavado a $121{ }^{\circ} \mathrm{C}$ por 20 minutos. Após resfriamento recebeu uma solução de $\mathrm{Zn}\left(\mathrm{SO}_{4}\right) 7 \mathrm{H}_{2} \mathrm{O}(100 \mathrm{ppm})$, previamente esterilizadas (ø $0,22 \mu \mathrm{m})$ a fim de obter zero; 2,$5 ; 5 ; 7,5 ; 10 ; 15$ e 20 ppm de zinco. Trinta $\mathrm{mL}$ de cada meio de cultivo foram transferidos para placas de petri $(\varnothing 11,5 \mathrm{~cm})$. Os meios foram inoculados com um disco de 8,0 milímetros de diâmetro, contendo micélio de $A$. subrufescens. O experimento foi realizado em decaplicata. $\mathrm{O}$ crescimento do fungo foi realizado a $28 \pm 1$ ${ }^{\circ} \mathrm{C}$ por 14 dias.

\section{Meio de Cultivo Líquido}

Extrato de malte $\left(20 \mathrm{~g} \mathrm{~L}^{-1}\right)$ foi transferido $(30 \mathrm{~mL})$ para Erlenmeyers de $125 \mathrm{~mL}$ e autoclavado a $121^{\circ} \mathrm{C}$ por 20 min. Após resfriamento recebeu diferentes volumes de solução de $\mathrm{Zn}\left(\mathrm{SO}_{4}\right) 7 \mathrm{H}_{2} \mathrm{O}(100 \mathrm{ppm})$, previamente esterilizadas (ø $0,22 \mu \mathrm{m})$, a fim de obter concentrações de zero; 2,$5 ; 5 ; 7,5$; $10 ; 15$ e 20 ppm de ferro ou zinco.

Os meios foram então inoculados com três discos de AEM (8,0 mm) contendo o micélio de A. subrufescens. O experimento foi realizado em decaplicata. $\mathrm{O}$ crescimento do fungo foi realizado a $28 \pm 1{ }^{\circ} \mathrm{C}$ por 14 dias.

\section{Obtenção da Biomassa}

A quantificação da biomassa micelial- para o fungo crescido em meio sólidos - foi realizada pelo aquecimento do meio de cultivo por 15 segundos em microondas (Electrolux MEF41-1000w) na potência alta. O micélio foi retirado, com auxílio de uma pinça e em seguida lavado três vezes com 80 $\mathrm{mL}$ de água ultra purificada a $80{ }^{\circ} \mathrm{C}$. O micélio foi centrifugado a $1699 \mathrm{~g}$ durante 15 minutos a $4{ }^{\circ} \mathrm{C}$. O excesso de água foi removido e a massa total de biomassa foi determinada após secagem a $60{ }^{\circ} \mathrm{C}$ em estufa com circulação de ar forçada. Para o meio de cultivo líquido a biomassa foi separada por centrifugação a $1699 \mathrm{~g}$ a $4{ }^{\circ} \mathrm{C}$ por $15 \mathrm{~min}$. A biomassa precipitada foi lavada (três vezes) com $30 \mathrm{~mL}$ de água ultra purificada e novamente centrifugada na mesma condição. A massa total de biomassa foi determinada após secagem a 60 ${ }^{\circ} \mathrm{C}$ em estufa com circulação de ar forçada.

\section{Concentração de Zinco na Biomassa}

Para a extração de minerais à biomassa micelial desidratada, foram adicionados 1:12 (m v'-1) de $\mathrm{HNO}_{3}(67 \%)$ e mantido em capela a temperatura ambiente por $48 \mathrm{~h}$. A mistura foi então aquecida a $100{ }^{\circ} \mathrm{C}$ e adicionada de $1: 6(\mathrm{~m}$ $\left.\mathrm{v}^{-1}\right)$ de $\mathrm{H}_{2} \mathrm{O}_{2}(30 \%)$ até completa solubilização do material. A mistura obtida foi filtrada em papel de filtro lavado e o volume exatamente ajustado para $50 \mathrm{~mL}$ com água ultrapurificada. A concentração de ferro das amostras foi determinada em Espectrofotômetro de Absorção Atômica de Chama (marca GBC modelo 932 plus) utilizando uma curva padrão para comparação e cálculo das concentrações. Todos os materiais utilizados em todas as fases experimentais foram lavados com solução de $\mathrm{HNO}_{3}(10 \%)$.

\section{Análise Estatística}

O ensaio foi confuzido em dielienamento inteiramente casualizado e os dados obtidos foram avaliados por análise de variância $(p \leq 0,05)$ e as diferenças entre as médias foram determinadas pelo teste de Tukey $(p \leq 0,05)$. 


\section{Resultados}

A adição de zinco no meio de cultivo aumentou $(p \leq 0,05)$ em até $43 \%$ o crescimento micelial de $A$. subrufescens no meio sólido para adições entre 2,5 e 10 ppm (Tabela 1). Já no meio de cultivo líquido, a adição de apenas $2,5 \mathrm{ppm}$ de zinco reduziu $(p \leq 0,05)$ a produção de biomassa em $76,8 \%$ e houve inibição de crescimento a partir de 7,5 ppm (Tabela 1). Desta forma, o fungo crescido em meio de cultivo sólido apresentou maior robustez para a manutenção da produção de biomassa na presença de até $10 \mathrm{ppm}$ de zinco.

Tabela 1: Biomassa e concentração de zinco do micélio de Agaricussubrufescens crescido em cultivo sólido ou líquido adicionado de diferentes concentrações de zinco na forma de $\mathrm{Zn}\left(\mathrm{SO}_{4}\right) 7 \mathrm{H}_{2} \mathrm{O}$.

\begin{tabular}{|c|c|c|c|c|}
\hline \multirow[b]{2}{*}{$\begin{array}{c}\text { Zinco } \\
\text { adiciona- } \\
\text { do (ppm) }\end{array}$} & \multicolumn{2}{|c|}{ Meio sólido } & \multicolumn{2}{|c|}{ Meio líquido } \\
\hline & $\begin{array}{c}\text { Biomassa } \\
\text { por placa } \\
(\mathrm{mg})\end{array}$ & $\begin{array}{c}\text { Zinco }(\mu \mathrm{g} \\
\mathrm{g}-1)\end{array}$ & $\begin{array}{c}\text { Biomassa } \\
\text { (mg mL- } \\
1)\end{array}$ & $\begin{array}{c}\text { Zinco }(\mu \mathrm{g} \\
\mathrm{g}-1)\end{array}$ \\
\hline $\begin{array}{c}\text { Controle } \\
\text { (zero) }\end{array}$ & $140 \pm 26^{\mathrm{a}}$ & $57 \pm 5^{\mathrm{e}}$ & $\begin{array}{l}1,90 \pm \\
0,13^{\mathrm{a}}\end{array}$ & $54 \pm 4^{c}$ \\
\hline 2,5 & $190 \pm 18^{\mathrm{a}}$ & $177 \pm 9^{d}$ & $\begin{array}{l}0,44 \pm \\
0,043^{b}\end{array}$ & $719 \pm 62^{b}$ \\
\hline 5 & $200 \pm 45^{\mathrm{a}}$ & $248 \pm 21^{c}$ & $\begin{array}{l}0,30 \pm \\
0,021^{\mathrm{b}}\end{array}$ & $972 \pm 28^{\mathrm{a}}$ \\
\hline 7,5 & $160 \pm 7^{a}$ & $414 \pm 13^{b}$ & nd & nd \\
\hline 10 & $160 \pm 30^{\mathrm{a}}$ & $473 \pm 21^{b}$ & nd & nd \\
\hline 15 & $80 \pm 6^{b}$ & $587 \pm 61^{\mathrm{a}}$ & nd & nd \\
\hline 20 & nd & nd & nd & nd \\
\hline
\end{tabular}

As médias seguidas pela mesma letra na mesma coluna, não diferem estatisticamente entre si pelo Teste de Tukey $(p \leq 0,05)$; nd: não determinado por ausência de crescimento micelial.

A adição de zinco ao meio de cultivo induziu a bioacumulação do metal tanto no cultivo sólido como no cultivo líquido (Tabela 1). Para o cultivo sólido a adição de 5 ppm de zinco aumentou a bioacumulação em até 4,35 vezes em relação ao controle. Já em meio líquido a adição de 5 ppm de zinco aumentou $(p \leq 0,05)$ a bioacumulação em 18 vezes. Dessa forma, a adição em meio de cultivo líquido favoreceu a bioacumulação de zinco para o micélio de $A$. subrufescens, no entanto, reduziu fortemente a produção de biomassa. Já no meio de cultivo sólido o fungo foi menos sensível à presença do Zn em que este promoveu crescimento micelial, porém, houve menor bioacumulação em comparação ao meio líquido. Desta forma, devido às maiores bioacumulações no meio de cultivo líquido este possui melhor aplicabilidade no processo biotecnológico para fortificação em basidiomicetos com este mineral.

\section{Discussão}

O aumento da concentração de zinco no meio de cultivo promoveu aumento da bioacumulação deste metal no micélio, tanto para o cultivo em meio sólido como líquido.O mecanismo de acúmulo de zinco em basidiomicetos está relacionado a expressão do gene HcZnT1 envolvido na homeostase do zinco,que é armazenado em compartimentos vesi- culares responsável pela manutenção celular de íons livres de zinco(BLAUDEZ; CHALOT, 2011).O aumento da biocumulação de zinco no micélio de $A$. subrufescens está relacionado a esses mecanismos de absorção e armazenamento, de forma que com o enriquecimento do meio de cultivo estes minerais tornam-se mais disponíveis.Outro aspecto importante que pode estar relacionado ao aumento da bioacumulação de metais pelos fungos é o gradiente de concentração formado intra e intercelularmente. Os resultados encontrados neste trabalho reforçam que o aumento de concentração de zinco no meio de cultivo, com consequente aumento do gradiente de concentração entre o micélio e o meio, aumentou a bioacumulação de minerais no micélio. Curdová et al. (2004) relatam que Pleurotus ostreatus, Schizophyllum commune, Daedalea quercina, Trametes versicolor e Pycnoporus cinnabarinus bio-acumularam concentrações de zinco no micélio entre 711 a $716 ; 500$ a 531; 111 a $142 ; 196$ a 216 e 623 a $656 \mu \mathrm{g} \mathrm{g}^{-1}$, respectivamente, em nove dias de crescimento em meio líquido adicionado de 6,5 ppm de zinco. Esses resultados se aproximam dos obtidos por A. subrufescens que neste trabalho apresentou uma bioacumulação de zinco de $972 \pm 28 \mu \mathrm{g} \mathrm{g}^{-1}$ em meio adicionado de 5ppm de zinco e demonstram o potencial de bioacumulação deste elemento no micélio de fungos basidiomicetos.

O fungo crescido em meio de cultivo sólido foi menos sensível a presença de Zn. Possivelmente houve interferência no processo de transporte de íons devido a presença de Agar como agente solidificante (WILLIANS, 1993). O ágar é um polímero que possui a capacidade de reter íons reduzindo a movimentação do mineral e a absorção pelo fungo, resultando assim em reduzidas taxas de bioacumulação. Já para o meio líquido há maior atividade de água que promove maior movimentação e contato dos íons com o fungo. Assim, o meio líquido adicionado de zinco resultou em maior bioacumulação e também maior toxicidade com forte redução do crescimento micelial.

Segundo, Peres e Koury (2006) a recomendação diária de zinco para uma pessoa adulta seria de $8 \mathrm{mg} \mathrm{dia}^{-1}$ para mulheres e $11 \mathrm{mg} \mathrm{dia}^{-1}$ para homens. As principais fontes de zinco consumidas pela população são farelo de soja $(0,031$ $\left.\mathrm{mg} \mathrm{g}^{-1}\right)$, feijão $\left(0,02 \mathrm{mg} \mathrm{g}^{-1}\right)$, leite integral $\left(3,732 \mathrm{mg} \mathrm{L}^{-1}\right)$, arroz integral $0,025\left(\mathrm{mg} \mathrm{g}^{-1}\right)$, peito de frango $\left(0,008 \mathrm{mg} \mathrm{g}^{-1}\right)$ e carne bovina $\left(0,03 \mathrm{mg} \mathrm{g}^{-1}\right)$. A ingestão de $3,88 \mathrm{~g}$ e $5,346 \mathrm{~g}$ de micélio produzido em meio líquido com adição de $5 \mathrm{ppm}$ se zinco seria suficiente para suprir $50 \%$ das necessidades diárias de zinco para mulheres e homens respectivamente.

\section{Conclusão}

A adição de zinco no meio de cultivo aumenta a bioacumulação deste composto no micélio de A. subrufescens tanto em cultivo líquido como sólido. O fungo crescido em meio de cultivo líquido sofre maior inibição do crescimento com a adição de zinco e maior bioacumulação. $\mathrm{O}$ meio de cultivo líquido possui melhor aplicabilidade no processo biotecnológico para produção de micélio de $A$. subrufescens bioacumulado com zinco.

\section{Agradecimentos}

Os autores agradecem à Universidade Paranaense 
- UNIPAR/PIBIC, CNPq/PEBIC e CAPES/PROSUP peloapoio à pesquisa em forma de bolsas de estudo.

\section{Referências}

ANDERSON, J. G.; ERIKSON, K. M. The Handbook of behavior, diet and nutrition. The importance of trace elements for neurological functioning. Sprin. Press. New York, USA, 2009, 3527p.

BLAUDEZ, D.; CHALOT, M. Characterization of the ER-located zinc transporter ZnT1 and identification of a vesicular zinc storage compartment in Hebelomacylindrosporum. Fungal Genetics Biology, v. 48. n. 5. p. 496-503, 2011.

BRAGA, G. C. et al. Manual de cultivo de Agaricus blazei Murril "cogumelo do sol". Fundação de Estudos e Pesquisas Agrícolas e Florestais. Botucatu. 1998, 44p.

CHANG, H. L. et al. Non-volatile taste components of Agaricusblazei, Antrodiacamphorata and Cordycepsmilitaris mycelia. Food Chemistry, v. 74. n. 2. p. 203-207, 2001.

CURDOVÁ, E. et al. ICP-MS determination of heavy metals insubmerged cultures of wood-rotting fungi.

Talanta, v. 62. n. 3. p. 483-487, 2004.

DELMANTO, R. D. et al. Antimutagenic effect of AgaricusblazeiMurrill mushroom on the genotoxicity induced by cyclophosphamide. Antimutagenesisanticarcino genesis, v. 496. n. 1. p. 15-21, 2001.

FAO Guidelines on food fortification with micronutrients. World Health Organization, Food and Agricultural Organization of the United Nations, 2006.

FIRENZUOLI, F.; GORI, L.; LOMBARDO, G. The medicinal mushroom AgaricusblazeiMurrill: review of literature and pharmaco-toxicological problems. EvidenceBased Complementary and Alternative Medicine, v. 5. n. 1. p. 3-15, 2008.

LINDE, G. A.; LAVERDE-JR, A.; COLAUTO, N. B. Handbook of behavior, food and nutrition. Changes to taste perception in the food industry: Use of Cyclodextrins, Sprin. Press. New York, USA, 2011.

\section{MANTOVANI, T. R. D. Criopreservação de fungos} lignocelulósicos e otimização de substratos a partir de resíduos agroindustriais. Umuarama, $\mathrm{PR}$, Brasil. 85 p. (M.Sc. Dissertação. Mestrado em Biotecnologia Aplicada à Agricultura. UNIPAR), 2008.

MOURÃO, F. Atividade biológica de Agaricus brasiliensis em diferentes fases de maturação do basidiocarpo. Umuarama, PR, Brasil. 73 p. (M.Sc. Dissertação. Mestrado em Biotecnologia Aplicada à Agricultura. UNIPAR), 2008.
PERES, P. M.; KOURY, J. C. Zinco, imunidade, nutrição e exercício. Ceres: Nutrição\&Saúde, v.1. n. 1. p. 9-18, 2006.

SANDSTEAD, H. H.; FREDERICKSON, C. J; PENLAND, J. G. History of zinc as related to brain function. Journal of Nutrition, v. 130. n. 2S. p. 496S-502S, 2000.

WILLIAMS, R. R.; Mineral nutrition "in vitro": a mechanistic approach. Australian Journal of Botany, v. 41. p. 237-251, 1993.

Recebido em: 01.12.2014 Aceito em: 29.12.2014 